\title{
Coronary Artery Spasm Discovered in Thorough Examination of Perioperative VT in a 26-year-old Japanese Male
}

\author{
Jin O-UCHI, ${ }^{1}$ MD, Kimiaki KomuKaI, ${ }^{1}$ MD, Jun-ichiro TOHYAMA, ${ }^{1}$ MD, \\ Keiichi InADA, ${ }^{1} \mathrm{MD}$, Keiji IwANO,${ }^{1} \mathrm{MD}$, Teiichi YAMAnE, ${ }^{1} \mathrm{MD}$, \\ Takahiro SHIBATA, ${ }^{1} \mathrm{MD}$, and Seibu MochIZUKI, ${ }^{1} \mathrm{MD}$
}

\begin{abstract}
SUMMARY
We thoroughly examined a 26-year-old Japanese male who experienced perioperative ventricular tachycardia. After inhaling sevoflurane, his nasal cavity was soaked with 1:100,000 epinephrine and he was intubated through the nose. Junctional tachycardia occurred five minutes after intubation, changing to ventricular tachycardia. Six-time cardioversion was required to stop the ventricular tachycardia. Echocardiography immediately following the event showed diffuse hypokinesis, and an electrocardiogram showed an inversion of $\mathrm{T}$ waves in II, III, ${ }_{\mathrm{a}} \mathrm{V}_{\mathrm{F}}$ and $\mathrm{V}_{4-6}$. Both returned to normal within a few days. Tl scintigraphy revealed a normal perfusion image. Coronary angiography showed a normal coronary, but an injection of acetylcholine induced vasospasm in the right coronary artery. Examination of left ventricular tissue yielded no specific findings. During electrophysiological tests, ventricular tachycardia could not be induced even in the presence of isoprenaline. This is a very young case to elicit vasospasm in the coronary artery with no underlying heart disease. Although the relationship between perioperative ventricular tachycardia and coronary spasm is unknown, cardiac events can occur during anesthesia in young and low-risk patients. (Jpn Heart J 2003; 44: 1021-1026)
\end{abstract}

Key words: Perioperative ventricular tachycardia, Epinephrine, Spasm

\section{CASE RePort}

A 26-year-old Japanese male (height: $174 \mathrm{~cm}$; weight: $68 \mathrm{~kg}$; smoking history; 8 years) was admitted to our hospital for surgery on a superior conchal cyst. Blood pressure was $120 / 64 \mathrm{mmHg}$ and heart rate was $51 \mathrm{bpm}$ and regular; there was no audible heart murmur. His preoperative chest X-ray and electrocardiogram showed no abnormalities. Hematological tests and urinalysis were within normal limits except for mild liver damage. The day of the operation, after inhalation of sevoflurane, his nasal cavity was soaked with 1: 100,000 epinephrine

From ${ }^{1}$ Division of Cardiology, Department of Internal Medicine, The Jikei University School of Medicine, Tokyo, Japan.

Address for correspondence: Kimiaki Komukai, MD, Division of Cardiology, Department of Internal Medicine, The Jikei University School of Medicine, Nishishinbashi 3-25-8, Minato-ku, Tokyo 105-8461, Japan.

Received for publication February 25, 2003.

Revised and accepted April 21, 2003. 
using a tampon and he was intubated through the nose. The ECG monitor before an inhalation of sevoflurane is presented in Figure 1 (upper trace). Approximately 5 minutes after intubation, heart rhythm indicated junctional tachycardia with ST segment depression (Figure 1, middle trace), progressing to ventricular tachycardia (Figure 1, bottom trace). His hemodynamic state was stable during the ventricular tachycardia. Intravenous xylocaine and isosorbide dinitrate were not effective and cardioversion was applied six times to stop the ventricular tachycardia.

An electrocardiogram immediately after the event demonstrated an inversion of the $\mathrm{T}$ wave in II, III, ${ }_{\mathrm{a}} \mathrm{V}_{\mathrm{F}}$, and $\mathrm{V}_{4}-\mathrm{V}_{6}$ (Figure 2). Echocardiography showed diffuse hypokinesis with an ejection fraction of $33 \%$. Left ventricular wall motion and electrocardiogram abnormalities recovered within a few days. Coronary angiography revealed a normal coronary artery. Administration of $100 \mu$ g acetylcholine into the left coronary artery induced severe narrowing in the proximal portion of the left anterior descending coronary artery (Figure 3). Administration of $20 \mu \mathrm{g}$ acetylcholine into the right coronary artery induced subtotal occlusion in a proximal portion with chest discomfort but without ischemic ECG change (Figure 4). Left ventricular tissue taken during the catheter procedure showed no specific findings. Tl scintigraphy at rest, MIBG scintigraphy, and the plasma catecholamine level were within normal limits. Electrophysiological tests were done, however, ventricular tachycardia could not be induced even in the presence
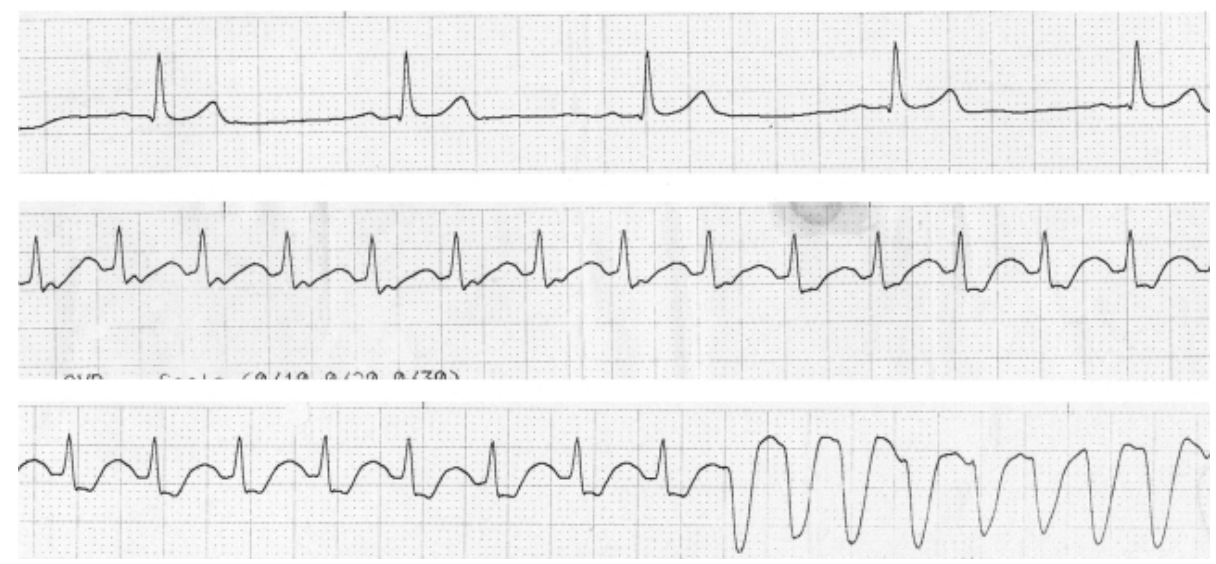

Figure 1. Heart rate monitor before and during ventricular tachycardia. 


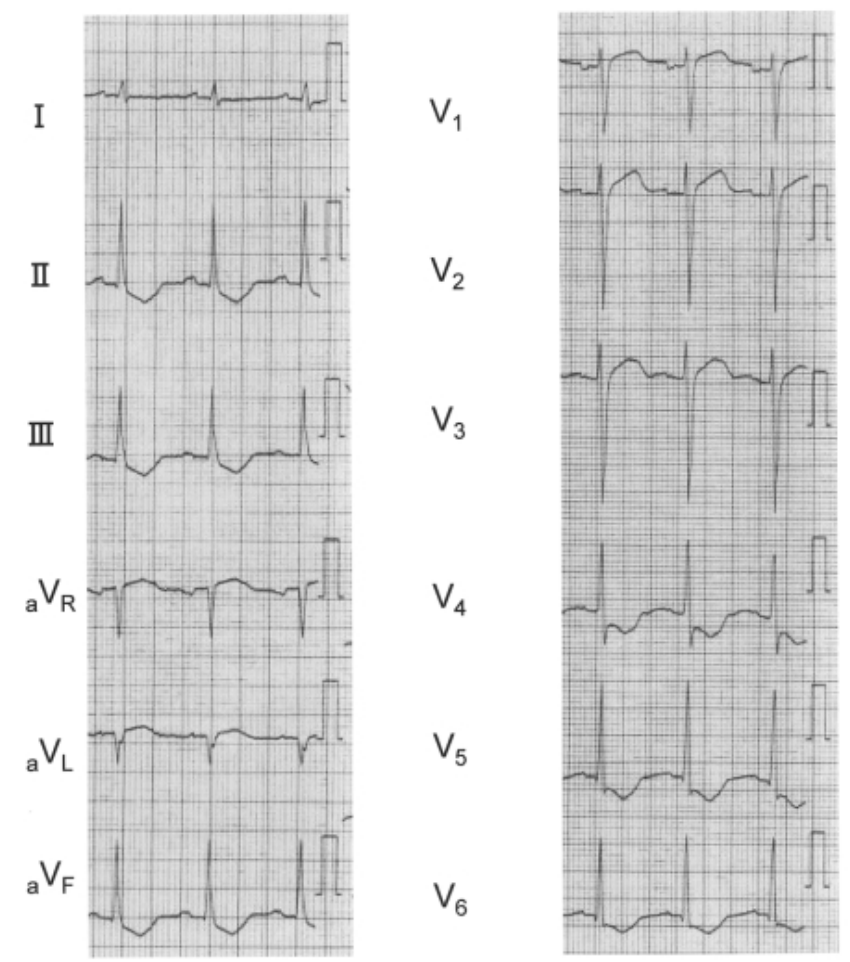

Figure 2. Electrocardiogram after recovery from ventricular tachycardia. $\mathrm{T}$ waves in II, III, ${ }_{\mathrm{a}} \mathrm{V}_{\mathrm{F}}$, and $\mathrm{V}_{4-6}$ were inverted.

A

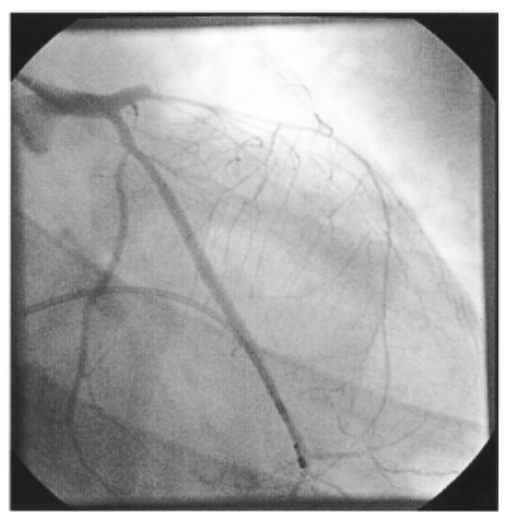

B

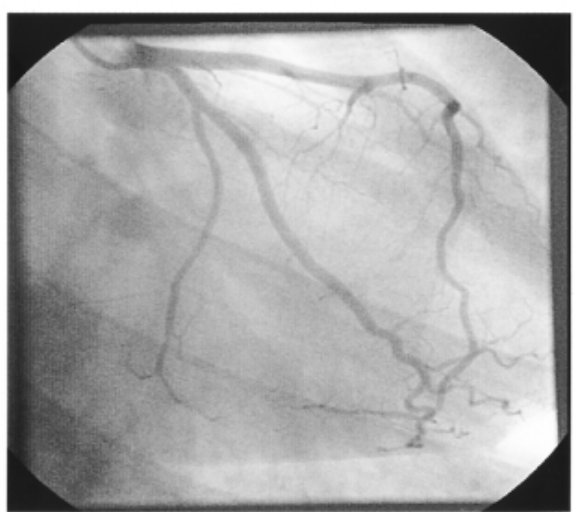

Figure 3. Administration of $100 \mu \mathrm{g}$ of acetylcholine into the left coronary artery induced severe stenosis in the left anterior descending artery (A); this was completely restored after the injection of isosorbide dinitrate (ISDN) (B). 


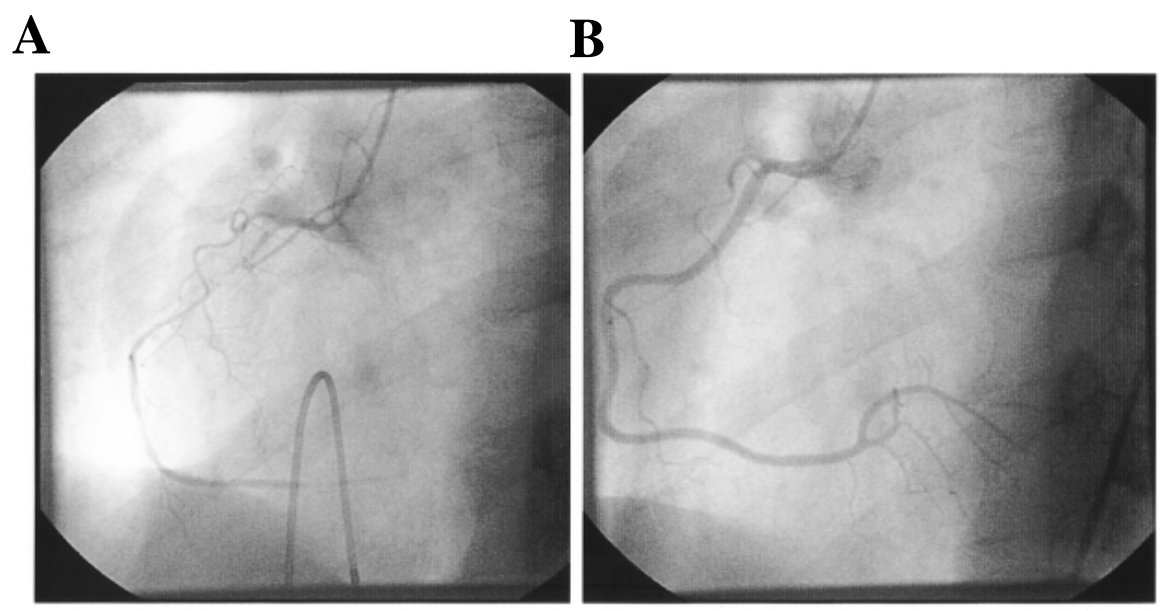

Figure 4. Administration of $20 \mu \mathrm{g}$ of acetylcholine into the right coronary artery induced subtotal stenosis (A); this was completely restored after the injection of ISDN (B).

of isoprenaline. A treadmill exercise test was also performed; again, ventricular tachycardia could not be induced.

\section{DISCUSSION}

We did a thorough examination to find the cause of the perioperative ventricular tachycardia, but we were unable to induce VT, only coronary artery spasm. The patient had no underlying heart disease such as sarcoidosis or amyloidosis and his family has no history of heart disease. A number of possibilities for the cause of perioperative ventricular tachycardia should be considered.

During anesthesia, infiltration with epinephrine can induce ventricular tachycardia. Volatile anesthetics are known to decrease the threshold for catecholamine-induced arrhythmia. ${ }^{1)}$ However, in this case, epinephrine was not injected, but his nasal cavity was soaked with 1:100,000 epinephrine; the serum epinephrine level should be much lower than the threshold for catecholamineinduced arrhythmia. The mechanism of catecholamine-induced arrhythmia is not clear, but beta-adrenoceptor stimulation is known to induce spontaneous $\mathrm{Ca}^{2+}$ oscillation; ${ }^{2}$ this may trigger ventricular tachycardia. However, the mechanism by which volatile anesthetics decrease the threshold for catecholamine-induced arrhythmia is unknown. Volatile anesthetics decrease intracellular $\mathrm{Ca}^{2+}$ transient ${ }^{3)}$ via an inhibition of the L-type $\mathrm{Ca}^{2+}$ current ${ }^{4)}$ which tends to decrease $\mathrm{Ca}^{2+}$ overload. Shortening of the action potential duration by volatile anesthetics ${ }^{4}$ might be 
one reason for the increase in catecholamine-induced arrhythmia during anesthesia.

Catecholamine cardiomyopathy can be induced by various types of stress. ${ }^{5}$ In these cases, ventricular wall motion usually shows basal hyperkineses and apical ballooning. Apical ballooning is also observed in rats experiencing emotional stress. ${ }^{6)}$ In contrast, the left ventricular wall motion in this patient showed diffuse hypokinesis. Moreover, this patient did not exhibit any abnormalities in MIBG scintigraphy or in a pathological examination of left ventricular tissue.

It appears possible that coronary artery spasm during anesthesia triggered ventricular tachycardia in this case. In the review by Koshiba and Hoka ${ }^{7)}$ of perioperative coronary spasm cases, the depth of general anesthesia is an important factor: in this case, the depth of anesthesia was adequate. While the administration of acetylcholine induced coronary artery spasm, it could not induce any arrhythmia in this case. The relationship between perioperative ventricular tachycardia and coronary artery spasm remains unclear.

Because coronary artery spasm is considered to be associated with damaged endothelial function, coronary artery spasm most commonly occurs in the elderly; ${ }^{8,9)}$ Ogawa, et al reported the incidence of spasm increases after age $30 .{ }^{9}$ ) While we cannot confirm that coronary spasm is the cause of the perioperative ventricular tachycardia in this case, an acetylcholine provocation test showed coronary artery spasm, and he is a very young case with no underlying heart disease. This case suggests that ventricular tachycardia can occur even in young and lowrisk patients during anesthesia.

\section{REFERENCES}

1. Hayashi Y, Sumikawa K, Tashiro C, Yamatodani A, Yoshiya I. Arrythmogenic threshold of epinephrine during sevoflurane, enflurane, and isoflurane anesthesia in dogs. Anesthesiology 1988; 69: 145-7.

2. Komukai K, Kurihara S. Effects of adenosine on $\mathrm{Ca}^{2+}$ transients and tension in aequorin-injected ferret papillary muscles. Pflugers Arch 1994; 428: 357-63.

3. Davies LA, Gibson CN, Boyett MR, Hopkins PM, Harrison SM. Effects of isoflurane, sevoflurane, and halothane on myofilament $\mathrm{Ca}^{2+}$ sensitivity and sarcoplasmic reticulum $\mathrm{Ca}^{2+}$ release in rat ventricular myocytes. Anesthesiology 2000; 93: 1034-44.

4. Rithalia A, Boyett MR, Hopkins PM, Harrison SM. Effects of halothane, isoflurane and sevoflurane on membrane currents in subepicardial and subendocardial rat left ventricular myocytes (Abstract). J Physiol (Lond.) 2002; 544P: 40P.

5. Tsuchihashi K, Ueshima K, Uchida T, et al. Transient left ventricular apical ballooning without coronary artery stenosis: a novel heart syndrome mimicking acute myocardial infarction. Angina pectoris-myocardial infarction investigations in Japan. J Am Coll Cardiol 2001; 38: 11-8.

6. Ueyama T, Kasamatsu K, Hano T, Yamamoto K, Tsuruo Y, Nishio I. Emotional stress induces transient left ventricular hypocontraction in the rat via activation of cardiac adrenoceptors - a possible animal model of 'takotsubo" cardiomyopathy. Circ J 2002; 66: 712-3.

7. Koshiba K, Hoka S. Clinical characteristics of perioperative coronary spasm: review of 115 case reports in Japan. J Anesth 2001; 15: 93-9. 
8. Okumura K, Yasue H, Matsuyama K, et al. Diffuse disorder of coronary artery vasomotility in patients with coronary spastic angina. Hyperreactivity to the constrictor effects of acetylcholine and the dilator effects of nitroglycerin. J Am Col Cardiol 1996; 27: 45-52.

9. Ogawa K, Numao T, Iizuka M, et al. Angiographic and coronary risk factor analyses of Japanese patients with ischemic heart disease before age 40 - a multicenter cooperative study. Jpn Circ J 1996: 60: 822-30. 